\title{
IgG subclasses in the serum and sputum from patients with bronchiectasis
}

\author{
S L Hill, J L Mitchell, D Burnett, R A Stockley
}

\begin{abstract}
Background-IgG subclass deficiency is often associated with recurrent pulmonary infections. The prevalence of deficiency in a large well characterised group of patients with bronchiectasis has not previously been established.

Methods-Serum IgG subclass concentrations in 89 patients with bronchiectasis were compared with those obtained from a group of 82 age and sex matched normal healthy controls. Sputum IgG subclass concentrations were also assessed in 44 of the patients. Albumin was measured as a marker of protein transudation from plasma to determine the degree of local IgG subclass production.
\end{abstract}

Results-The serum concentrations of $\operatorname{IgG}_{1}, \operatorname{IgG}_{2}$ and $\operatorname{IgG}_{3}$ were increased in the patients compared with the control group whereas IgG $_{4}$ concentrations were not. There was an overall incidence of deficiency of $1 \%$ for subclasses $1-3$ and $5 \%$ for subclass 4 in patients with bronchiectasis based on observed concentrations being below the lower limit of the control group range. The concentrations of IgG subclasses in sputum were partly dependent upon the degree of inflammation as assessed by the macroscopic appearance of purulence. A comparison of the ratio of sputum:serum subclass concentration and sputum:serum albumin, however, revealed that all of the subclasses were present at greater concentrations than could be accounted for by transudation alone.

Conclusions-A new normal control range for serum IgG subclasses has been established and from this range it was found that IgG subclass deficiency in a group of unselected patients with bronchiectasis was comparatively rare. A significant degree of local IgG production was also suggested in the lungs of these patients.

(Thorax 1998;53:463-468)

Keywords: IgG subclasses; bronchiectasis; sputum; normal ranges

IgG subclasses have been measured in patients with chronic or recurrent respiratory infections by several groups and estimates of the incidence of deficiency of one or more of the subclasses in these patients has been as high as $38 \%{ }^{1}$ This has led various authors to suggest that these disease conditions may be associated with a variety of single or combined subclass deficiencies, notably $\mathrm{IgG}_{2},{ }^{2}{ }^{3} \mathrm{IgG}_{3},{ }^{1} \mathrm{IgG}_{4},{ }^{24}$ or the combination $\operatorname{IgG}_{2}$ and $\operatorname{IgG}_{4}$. $^{5}$
Differences in the incidence of deficiency reported in patients by various groups can often be explained by the source and nature of the normal range used for comparison. The values from as few as 20 individuals have been used to define normal limits for healthy adults, ${ }^{6}$ and ranges have been established using a variety of criteria - for example, the entire range of values derived from control samples, ${ }^{6}$ the 5 th and 95th percentiles, ${ }^{7}$ or two standard deviations about the mean. ${ }^{12}$ The last definition relies on a normal distribution of values. As previously suggested, both this and the use of percentile ranges would naturally identify a proportion of normal healthy individuals as being subclass deficient. ${ }^{8}$ This was illustrated in a study of $\operatorname{IgG}_{2}$ levels in healthy blood donors where the levels were not normally distributed and more subjects had values greater than 3SD below the mean than would be predicted. ${ }^{9}$ Furthermore, the use of different laboratory immunoassays to establish normal ranges and patient values may also account for discrepancies in the results from various groups.

A final problem relates to the patient groups studied, since many reports include a heterogeneous population with either persistent or intermittent respiratory infection with the results subsequently applied to specific disease entities. IgG subclass deficiency in bronchiectasis is thought to be associated with the development of the condition. ${ }^{10}$ There were, until recently, two major studies in this patient group, both of which suggested that the incidence of IgG subclass deficiency is low, ${ }^{11} 12$ and in one of these studies the control group consisted of patients with established lung disease rather than healthy subjects. However, a recent study from Spain in patients with bronchiectasis ranging in age from 10-74 years has suggested a much higher incidence. ${ }^{13}$ This group used a percentile range from control values which, as discussed above, naturally identifies a proportion of normal individuals as deficient. The true incidence of deficiency in bronchiectasis is thus unclear. Identification of IgG deficiency in these patients is important since benefit may be derived from replacement therapy. However, local antibody production in the lung may be more important than serum immunoglobulin levels, particularly as the lung is the site of infection and inflammation in these patients, and would therefore be important in antibody dependent clearance mechanisms although this aspect has yet to be evaluated in bronchiectasis.

The purpose of the studies reported in this paper is twofold; firstly, to establish the incidence of serum IgG deficiency in a large 
group of patients with bronchiectasis compared with age and sex matched healthy control subjects, and secondly,to assess the presence of IgG subclasses in the lung secretions of patients with bronchiectasis and to determine the extent of local in situ production.

\section{Methods}

PATIENTS AND CONTROLS

Eighty nine patients with bronchiectasis (55 women) of mean age 58.4 years (range 23-81) were studied. The diagnosis of bronchiectasis was established radiologically by bronchography or high resolution CT scanning. The aetiology of the disease was unknown although in most patients the onset of symptoms followed a childhood illness such as whooping cough or pneumonia. All 89 patients had a persistent cough and daily sputum production, only two were current smokers but most (51) had never smoked. None had cystic fibrosis or $\alpha_{1}$-antitrypsin deficiency. All were regularly attending a specialist bronchiectasis clinic and were clinically stable at the time of being studied with no evidence of pyrexia or acute increase in cough, breathlessness, or sputum production. None of the 89 patients had received antibiotic therapy within the four week period preceding the study. All patients provided a $10 \mathrm{ml}$ venous blood sample and the serum was obtained by low speed centrifugation and stored at $-40^{\circ} \mathrm{C}$ until analysed. Sputum samples (collected into sterile containers for four hours from waking) were provided at the same time by 44 of the patients ( 28 women) of mean age 60.7 years (range 39-81) and were classified as mucoid, mucopurulent, or purulent according to the macroscopic appearance of the samples as previously described. ${ }^{14}$
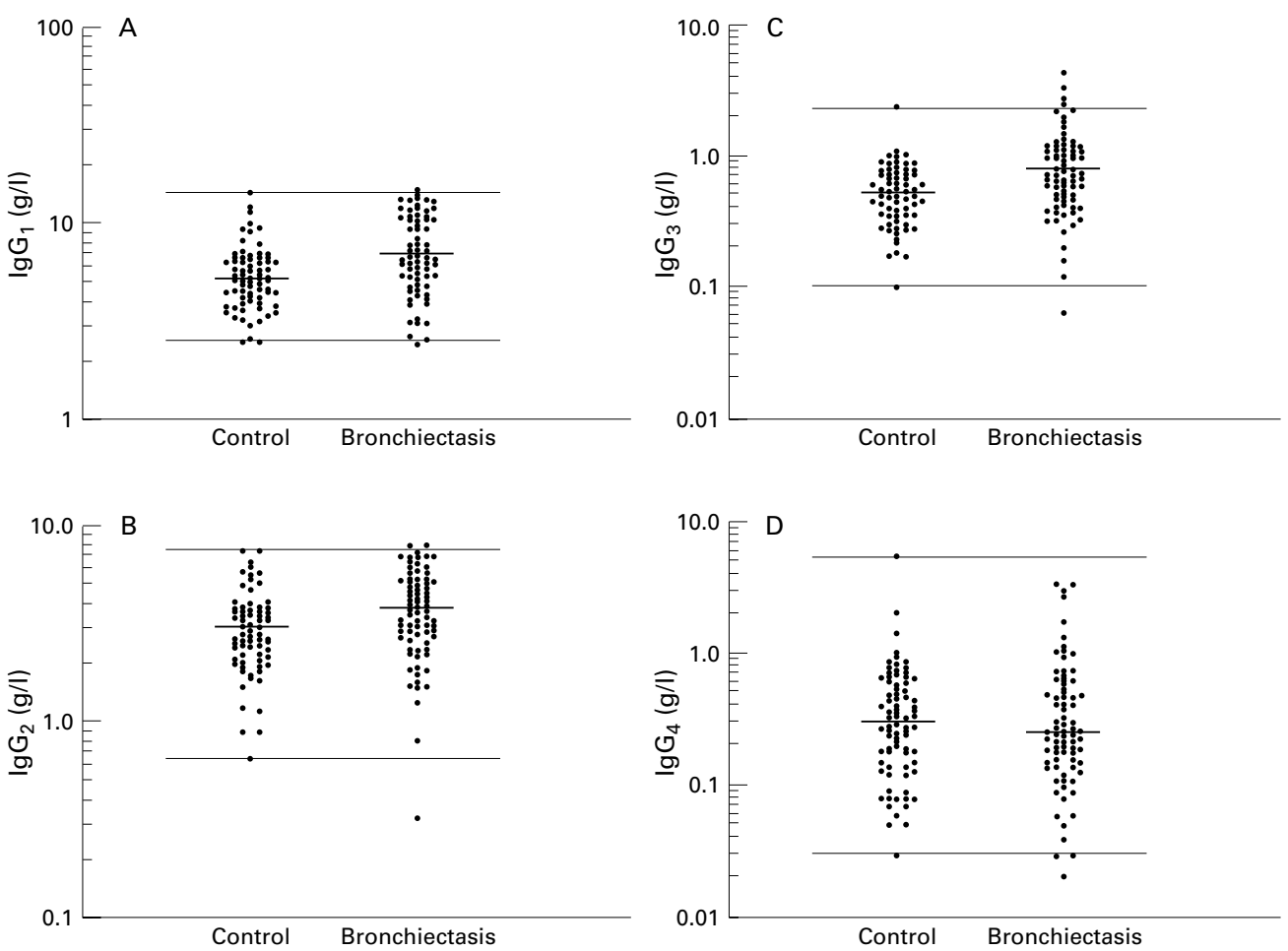

Sputum sol phase was obtained by refrigerated high speed centrifugation $(50000 \mathrm{~g})$ for 90 minutes and stored at $-40^{\circ} \mathrm{C}$ until analysed.

In addition, venous blood was collected from 82 normal healthy subjects (51 women) of mean age 56.9 years (range 22-90) and serum was obtained. None of these control subjects had a history of chronic respiratory disease or recurrent respiratory tract infections (11 were current smokers). None was suffering from acute upper or lower respiratory tract infection or receiving any prescribed medication at the time of the study.

MATERIALS AND LABORATORY METHODS

The four IgG subclasses were measured in serum samples from patients and controls and in sol phase sputum from patients by radial immunodiffusion using prepoured plates (The Binding Site, Birmingham, UK) containing subclass specific sheep polyclonal antisera. Subclass concentrations of the samples were obtained by reference to purified protein standards applied in accordance with the manufacturer's recommendations. The lower limit of detection was $0.0025 \mathrm{~g} / 1$ for each $\mathrm{IgG}$ subclass and within batch coefficients of variation (CV) were equal to or less than $5 \%$ for all subclasses in sputum and serum $(n=6)$. The between batch CV was less than $8 \%$ for each subclass $(n=6)$, confirming the reproducibility of these assays for the measurement of IgG subclasses in both sputum and serum samples.

To determine the possibility of IgG subclasses in sputum being under or overestimated, samples of mucoid, mucopurulent, and purulent sputum were measured before and after the addition of a known quantity of purified IgG subclass (The Binding Site, Birmingham, UK).

Figure 1 (A-D) IgG subclass concentrations in serum from 89 patients with bronchiectasis and 82 healthy control subjects. Medians are indicated by solid lines. 
Table 1 Median values (and ranges) of IgG subclasses in sputum and serum from 44 patients with bronchiectasis

\begin{tabular}{|c|c|c|c|}
\hline & \multicolumn{3}{|l|}{ Nature of sputum } \\
\hline & Mucoid & Mucopurulent & Purulent \\
\hline \multicolumn{4}{|l|}{$\operatorname{IgG}_{1}$} \\
\hline Serum $(\mathrm{g} / \mathrm{l})$ & $6.77(2.6-13.6)$ & $10.61(4.4-13.4)$ & $7.17(3.9-13.9)$ \\
\hline Sputum $(\mathrm{g} / \mathrm{l})$ & $0.10(0.01-0.26)$ & $0.26(0.1-0.37)$ & $0.40(0.24-1.3)$ \\
\hline Sputum (\% serum) & $1.47(0.1-7.8)$ & $2.53(0.9-7.5)$ & $5.99(2.5-12.7)$ \\
\hline Ratio corrected for albumin & $1.42(0.2-7.6)$ & $1.84(0.1-15.3)$ & $3.20(0.8-6.8)$ \\
\hline \multicolumn{4}{|l|}{$\mathrm{IgG}_{2}$} \\
\hline Serum $(g / 1)$ & $4.33(1.5-7.0)$ & $3.03(1.5-6.9)$ & $4.07(1.8-7.8)$ \\
\hline Sputum $(\mathrm{g} / \mathrm{l})$ & $0.06(0.01-0.32)$ & $0.16(0.06-0.49)$ & $0.23(0.05-0.5)$ \\
\hline Sputum (\% serum) & $1.73(0.2-4.9)$ & $6.4(1.3-27.6)$ & $5.74(1.8-13.8)$ \\
\hline Ratio corrected for albumin & $1.38(0.3-6.8)$ & $7.03(0.4-26.7)$ & $2.13(0.9-14.0)$ \\
\hline \multicolumn{4}{|l|}{$\mathrm{IgG}_{3}$} \\
\hline Serum $(g / 1)$ & $0.66(0.2-2.8)$ & $0.79(0.4-1.5)$ & $1.15(0.4-4.4)$ \\
\hline Sputum (g/l) & $0.03(0.002-0.1)$ & $0.13(0.06-0.22)$ & $0.22(0.07-0.3)$ \\
\hline Sputum (\% serum) & $4.17(0.3-40.6)$ & $12.5(5.9-45.7)$ & $16.92(3.2-54.7)$ \\
\hline Ratio corrected for albumin & $3.65(1.2-32.0)$ & $11.19(1.9-69.1)$ & $8.33(0.8-46.3)$ \\
\hline \multicolumn{4}{|l|}{$\mathrm{IgG}_{4}$} \\
\hline Serum $(\mathrm{g} / \mathrm{l})$ & $0.29(0.1-1.0)$ & $0.19(0.1-3.4)$ & $0.20(0.1-1.4)$ \\
\hline Sputum $(g / 1)$ & $0.04(0-0.22)$ & $0.11(0.03-0.3)$ & $0.21(0-0.28)$ \\
\hline Sputum (\% serum) & $6.44(0.4-162.9)$ & $52.63(2.9-175)$ & $32.18(18.3-172)$ \\
\hline Ratio corrected for albumin & $5.90(0.4-128.3)$ & $24.79(0.7-193)$ & $12.12(3.7-113)$ \\
\hline
\end{tabular}

Median values of sputum expressed as a percentage of serum are also shown together with this ratio corrected for the ratio of sputum to serum albumin. Values are divided into the three categories according to the usual nature of secretions produced by the patient when clinically stable.

No major overestimation was observed, with results varying from $+5 \%$ to $-20 \%$ of the predicted value.

Albumin in serum and sputum from the 44 patients (where sputum was collected) was measured by radial immunodiffusion using $1 \%$ agarose in $0.1 \mathrm{M}$ barbitone buffer ( $\mathrm{pH}$ 8.6) containing 3\% polyethylene glycol 8000 and sheep polyclonal antibody to human albumin (The Binding Site, Birmingham, UK). Plates were incubated at room temperature for 48 hours and the precipitation ring diameter was measured to
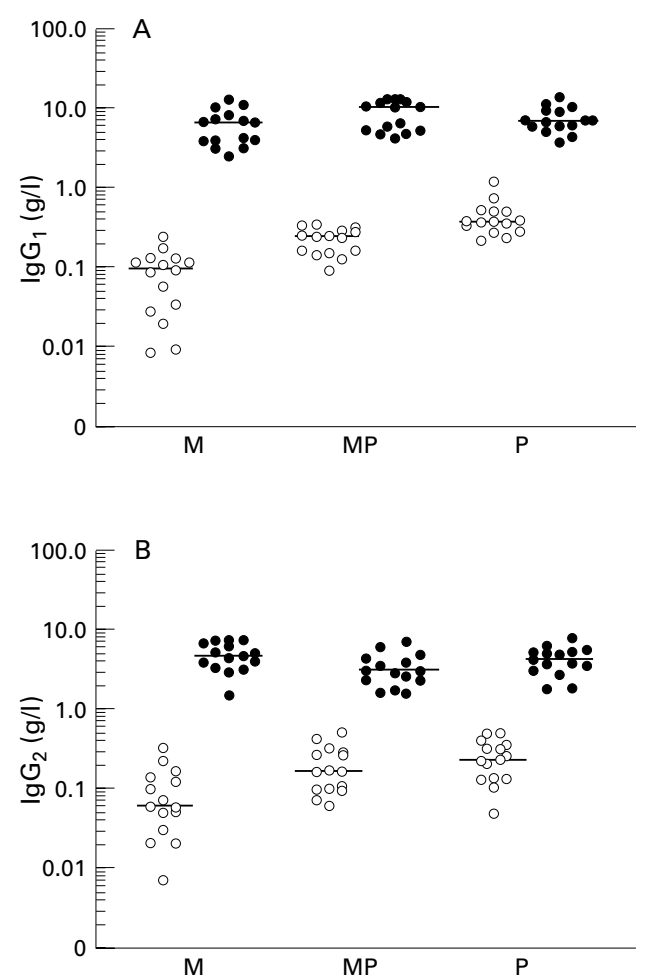

the nearest $0.5 \mathrm{~mm}$. Albumin values were obtained by interpolation from a standard curve constructed from a pooled normal serum standard $(44.4 \mathrm{~g} / \mathrm{l})$. The lower limit of detection of the assay was $0.03 \mathrm{~g} / 1$, within batch $\mathrm{CV}$ was $7 \%(\mathrm{n}=$ $6)$, and between batch CV was $9 \%(n=5)$.

\section{STATISTICAL METHODS}

Serum IgG subclass values in patients were compared with control subjects. Deficiency of IgG subclass levels in the patient group was identified as values which fell below the lower limit of the control group. Sputum IgG subclass values were divided according to the nature of the secretions (mucoid, mucopurulent, and purulent) and compared. Sputum: serum albumin ratios were calculated and compared with sputum:serum IgG subclass ratios to assess the contribution of transudation from plasma and hence the inferred degree of local production as described previously. ${ }^{15}$ All data were expressed as medians and ranges. Differences between groups were analysed using the Mann-Whitney U test for non-parametric data (paired and unpaired, where appropriate) and accepted as significant at $\mathrm{p}<0.05$.

\section{Results}

SERUM IgG SUBCLASSES

All subclasses were detected in each serum sample obtained from both patients and healthy control subjects. The individual values and the medians and ranges for the patients with bronchiectasis and healthy subjects are shown in fig $1 \mathrm{~A}-\mathrm{D}$. In patients the median serum concentration of $\mathrm{IgG}_{1}$ was $6.89 \mathrm{~g} / \mathrm{l}$ (range $2.50-14.87$ ), for $\mathrm{IgG}_{2}$ was $3.74 \mathrm{~g} / 1(0.32-7.81)$, and for $\mathrm{IgG}_{3}$
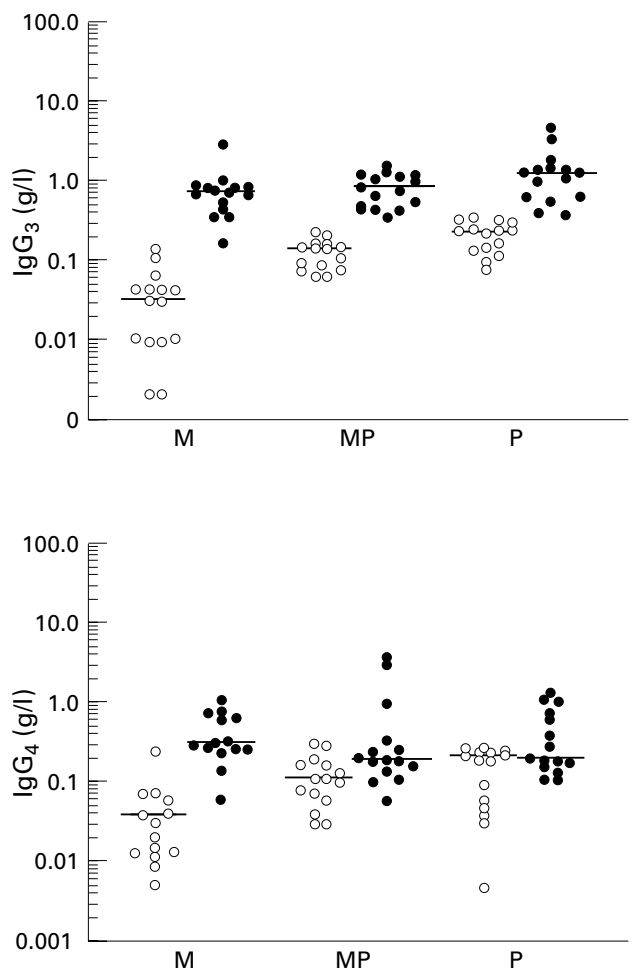

Figure $2(A, B)$ IgG subclass concentrations in paired sputum and serum samples from patients with bronchiectasis. Median values are indicated by a solid line. Open circles represent sputum values and closed circles represent serum values. The values are divided into the three sputum colour categories ( $M=$ mucoid; $M P=$ mucopurulent; $P=$ purulent $)$. 


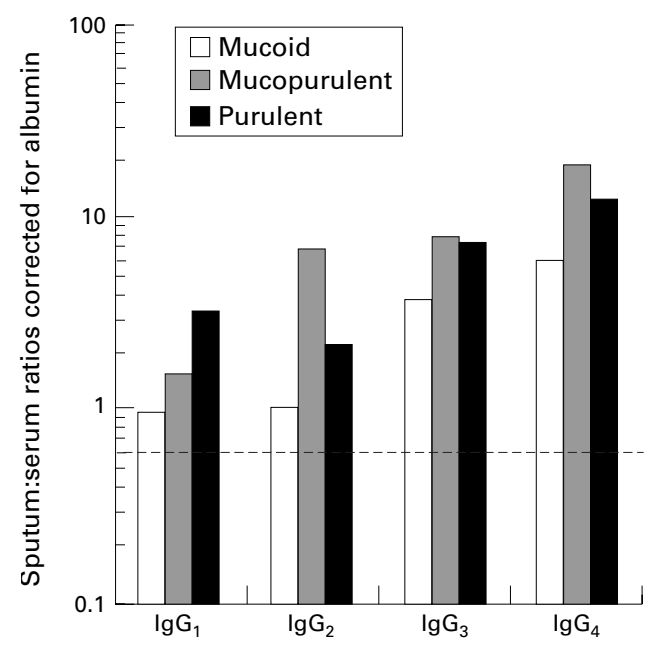

Figure 3 Median sputum:serum IgG subclass ratios corrected for the sputum:serum ratio of albumin. The dashed line represents the expected ratio if both $\operatorname{IgG}$ and albumin enter the lung by diffusion alone. The results are shown divided into the three sputum colour categories.

was $0.79 \mathrm{~g} / 1(0.06-4.38)$. These were significantly higher $(\mathrm{p}<0.001)$ than the median concentrations observed in the control subjects $\left(\operatorname{IgG}_{1} 5.25 \mathrm{~g} / 1\right.$, range $2.52-14.12 ; \operatorname{IgG}_{2} 2.91 \mathrm{~g} / 1$, range $0.63-7.28 ; \mathrm{IgG}_{3} 0.5 \mathrm{~g} / \mathrm{l}$, range 0.10 2.30). Values for $\mathrm{IgG}_{4}$ (median $0.26 \mathrm{~g} / 1$, range 0.02-3.41) were similar to the control group (median $0.31 \mathrm{~g} / 1$, range $0.03-5.51$ ).

Six patients had values at or below the lower end of the normal range. One patient had a low $\mathrm{IgG}_{1}$ level, one a low $\mathrm{IgG}_{3}$ level, four had low $\mathrm{IgG}_{4}$ levels (one patient also had low levels of $\mathrm{IgG}_{2}$ ). Based on the established healthy control range, the overall deficiency of $\operatorname{IgG}_{1}, \mathrm{IgG}_{2}$, and $\mathrm{IgG}_{3}$ was $1 \%$ and was slightly higher $(5 \%)$ for $\mathrm{IgG}_{4}$ in this patient group.

SPUTUM IgG SUBCLASSES

The 44 patients who also supplied sputum samples had serum IgG subclass concentrations within the normal range established from the control group as shown in table 1. There was no relationship between serum subclass concentration and the nature of the secretions produced by these patients (table 1, fig 2A, B). All immunoglobulin subclasses were identified in each sputum sample studied, with the exception of two samples in which $\mathrm{IgG}_{4}$ was undetectable $(<0.0025 \mathrm{~g} / \mathrm{l})$. The median sputum concentrations and ranges are shown in table 1 and fig 2 . In general, the concentration of subclasses in each secretion was in the order $\operatorname{IgG}_{1}>\mathrm{IgG}_{2}>\mathrm{IgG}_{3}>\mathrm{IgG}_{4}$.

The median sputum concentration of all subclasses generally increased with purulence. This increase was significant between mucoid and mucopurulent samples $(\mathrm{p}<0.005)$ and mucoid and purulent samples $(\mathrm{p}<0.001)$ for all subclasses. Differences between mucopurulent and purulent samples were only observed for $\operatorname{IgG}_{1}$ and $\operatorname{IgG}_{3}(\mathrm{p}<0.005)$.

IgG subclass concentrations were lower in sputum than in serum, with the exception of $\mathrm{IgG}_{4}$ in some samples (fig $2 \mathrm{~B}$ ). The median concentration of $\operatorname{IgG}_{1}$ and $\mathrm{IgG}_{2}$ in mucoid sputum was $1-2 \%$ of the serum value (table 1 ), whereas the relative concentration of $\mathrm{IgG}_{3}$ and $\mathrm{IgG}_{4}$ in sputum was higher, being $4 \%$ and $6 \%$ of the serum value, respectively. The ratio of sputum:serum concentration for $\operatorname{IgG}_{1}$ increased progressively from mucoid to mucopurulent samples $(\mathrm{p}<0.01)$ and mucopurulent to purulent samples $(\mathrm{p}<0.001)$ as shown in table 1 . In subclasses $\operatorname{IgG}_{2}, \operatorname{IgG}_{3}$, and $\operatorname{IgG}_{4}$ the ratio of sputum:serum concentration increased from mucoid to mucopurulent secretions $(\mathrm{p}<0.01)$ but no further increase was observed in purulent samples (table 1). A similar pattern emerged when the sputum:serum IgG subclass ratios were corrected for the sputum:serum ratio of albumin to assess local production (table 1, fig 3), although fewer differences reached statistical significance $\left(\operatorname{IgG}_{1}\right.$, mucoid to purulent: $\mathrm{p}<0.01 ; \operatorname{IgG}_{2}$ mucoid to mucopurulent: $\mathrm{p}<0.001 ; \mathrm{IgG}_{3}$ mucoid to mucopurulent or purulent: $\mathrm{p}<0.02$; and $\mathrm{IgG}_{4}$ mucoid to mucopurulent or purulent: $\mathrm{p}<0.05$ ).

\section{Discussion}

This study establishes a new range for serum IgG subclasses in healthy adults. The entire range of values from this group of control subjects was compared with values obtained from patients with bronchiectasis in order to determine the incidence of IgG subclass deficiency in this chronic lung disease. The two groups were of equivalent size and were matched for age and sex. All measurements were made by the same laboratory using consistent measurement techniques. Examination of the control range described here reveals that the lower limit for each subclass was consistently lower than those of control ranges published previously, ${ }^{691216}$ which is probably due to our use of the entire range of measured values instead of 95th and 97th centile ranges or two standard deviations from the mean. French and Harrison have already shown that the frequency distributions of IgG subclasses in the serum of healthy adults is skewed, and that the use of the entire range or 95th centile range for each subclass is more acceptable than ranges defined by standard deviations.

Using our control range, six patients with bronchiectasis $(6.6 \%)$ had serum IgG subclass values lower than healthy subjects, and the relative deficiency in this sample population was $1 \%$ for $\operatorname{IgG}_{1}, \operatorname{IgG}_{2}$ and $\operatorname{IgG}_{3}, 5 \%$ for $\mathrm{IgG}_{4}$, and $1 \%$ for $\mathrm{IgG}_{2}$ and $\mathrm{IgG}_{4}$ in combination. The most widely quoted normal range is that of Oxelius and colleagues ${ }^{6}$ and, using that range, 12 of our patients would be classified as having $\mathrm{IgG}_{1}$ deficiency, two $\mathrm{IgG}_{2}$ deficiency, $12 \mathrm{IgG}_{3}$ levels below and three at the limit of the range, and one with $\operatorname{IgG}_{4}$ deficiency $(13 \%, 2 \%, 13 \%$, and $1 \%$, respectively). The range we describe is wider than that reported by Oxelius et $a l,{ }^{6}$ probably because their group only consisted of 20 healthy subjects and different laboratory methods were used. It would appear that our normal control range is more relevant, particularly since the same measurement techniques were used throughout and the whole of the normal age and sex matched control range was employed for comparative purposes. The results presented here show that serum IgG 
subclass levels in this group of adult patients with bronchiectasis associated with chronic sputum production are predominantly normal. In addition, the data presented here indicate that the IgG levels for the group as a whole ware higher than the normal healthy control subjects. This latter finding is consistent with data published by other workers, ${ }^{11}{ }^{12}$ suggesting increased activity of the immune system in response to chronic infection.

The studies here, however, conflict with the results of the study by de Gracia and colleagues ${ }^{13}$ who reported that $48 \%$ of patients with bronchiectasis had low serum concentrations of IgG subclasses. The majority of patients classified as deficient had low levels of $\mathrm{IgG}_{2}(29 \%)$ with no reported deficiency of $\operatorname{IgG}_{1}$ and similar incidences of $\mathrm{IgG}_{3}$ and $\mathrm{IgG}_{4}$ deficiency ( $3 \%$ and $4 \%$, respectively). This may reflect the use of a percentile control range where the lower limits for each of the four IgG subclasses were much higher than the lowest limits observed in the healthy control subjects reported here. Our data support the previous suggestion that the use of such ranges naturally identifies a proportion of healthy individuals as being subclass deficient. ${ }^{8}$ This is particularly relevant to the $\operatorname{IgG}_{2}$ subclass results since, in the study by de Gracia and colleagues, ${ }^{13}$ the lower limit of their control range was $1.1 \mathrm{~g} / 1$ compared with $0.63 \mathrm{~g} / 1$ which was the lowest value measured in the healthy control range in this study. From the data provided in the paper by de Gracia and colleagues ${ }^{13}$ it was not possible to re-calculate the number of their patients who would remain IgG subclass deficient when compared with our control range and whether this was related to the younger age of the patients they studied (10-74 years).

Studies of serum IgG subclasses, however, are probably more relevant to systemic infections than they are to infections of the mucosal surface where local IgG production also occurs, ${ }^{17} 18$ and we have therefore studied IgG subclasses in secretions from some of the patients. Protein diffusion from plasma is responsible for a proportion of the immunoglobulin found in secretions, and this component increases with inflammation. ${ }^{15}$ Previous studies from our laboratory have shown that inflammation correlates positively with sputum purulence in patients with bronchiectasis, ${ }^{19}$ and therefore part of the increased sputum IgG levels (expressed in absolute concentrations or as \% serum in table 1) in mucopurulent and purulent secretions will reflect increased transudation from plasma. In addition, a proportion of the IgG may be locally produced by resident lymphocytes and this may also increase with lung inflammation as has been shown for IgA and confirmed by staining of IgA subclass bearing plasma cells in bronchiectatic lung tissue. ${ }^{20}$

Absolute concentrations of $\mathrm{IgG}_{1}$ and $\mathrm{IgG}_{2}$ exceeded those of $\mathrm{IgG}_{3}$ and $\mathrm{IgG}_{4}$ in all sputum samples assayed, and in purulent samples the concentrations of all IgG subclasses were greater than in mucoid samples. This, in part, reflects greater protein transudation from plasma which has been shown to be present in purulent sputum samples ${ }^{19}$ but the data also suggest an increase of local production. Separating local production from that due to transudation from plasma can be difficult. There can be little doubt that there is a major degree of local $\mathrm{IgG}_{4}$ production because in some samples the sputum concentration exceeded that found in serum (fig 2). Comparison with albumin can provide some clarification for other samples and subclasses because it enters the lung by diffusion from plasma. ${ }^{21}$ If the albumin concentration in sputum is expressed as a percentage of its concentration in serum and compared with the corresponding value for each IgG subclass, a ratio of approximately 0.6 will result if both proteins are entering the lung by diffusion alone. ${ }^{22}$ It has therefore been suggested that ratios greater than 0.6 indicate significant local production. ${ }^{22}$ Comparison of the observed ratio with the expected ratio (0.6) enables an approximate estimate of the amount produced locally to be made.

The median value of the albumin-corrected ratio exceeded 0.6 for all subclasses in each sputum category studied (table 1). The proportion produced locally also showed some differences between subclasses. In mucoid sputum samples approximately $50-60 \%$ of the $\mathrm{IgG}_{1}$ and $\mathrm{IgG}_{2}$ was produced in the lung (median ratios compared with albumin 1.42 and 1.38, respectively), whereas local production accounted for $80-90 \%$ of the $\operatorname{IgG}_{3}$ and $\mathrm{IgG}_{4}$ (median ratios compared with albumin 3.65 and 5.90, respectively). Overall, the absolute concentrations of $\operatorname{IgG}_{1}$ and $\mathrm{IgG}_{2}$ still predominated in these secretions (table 1 ). In purulent samples the absolute concentrations of all IgG subclasses were greater than in the mucoid samples. Although this reflects increased protein transudation associated with inflammation, there is also evidence for increased local production. Between $70 \%$ and $80 \%$ of the $\operatorname{IgG}_{1}$ and $\mathrm{IgG}_{2}$ in purulent samples was produced locally, as indicated by median ratios compared with albumin of 3.20 and 2.13 , respectively. This increased proportion of local production also rose to $93 \%$ for $\mathrm{IgG}_{3}$ and $95 \%$ for $\mathrm{IgG}_{4}$, with median ratios compared with albumin of 8.33 and 12.12 , respectively. The absolute amount of $\operatorname{IgG}_{1}$ and $\mathrm{IgG}_{2}$, however, still exceeded that of $\mathrm{IgG}_{3}$ and $\mathrm{IgG}_{4}$ in these samples.

The results therefore suggest that there is significant local production of all IgG subclasses in the lungs of these patients with bronchiectasis. This local production increases in the presence of purulent secretions, indicating an enhanced local immune response where neutrophil infiltration and the presence of neutrophil elastase has been demonstrated. ${ }^{10} 19$ These general conclusions, however, are based upon median values and the assumed contribution of immunoglobulin by diffusion from plasma. Individual values showed a wide range and in two subjects $\operatorname{IgG}_{4}$ was not detected in the sputum (see results). Both subjects had serum $\mathrm{IgG}_{4}$ levels within the normal range of this study (0.28 and $0.19 \mathrm{~g} / 1$, respectively), but it should be noted that the presence of $\mathrm{IgG}_{4}$ in 
the plasma does not guarantee its detection in secretions. The diffusion gradient, even in the presence of inflammation, results in approximately $1-3 \%$ of plasma protein entering the secretions ${ }^{19}$ and this would be beneath the limit of detection of the assay for $\mathrm{IgG}_{4}$ for all samples. Thus, the presence of detectable $\mathrm{IgG}_{4}$ in the secretions is largely dependent upon local production. The failure to identify $\mathrm{IgG}_{4}$ in the secretions of these two patients suggests a possible absence of local production in the lung. An alternative possibility is the binding of antibody to bacterial antigens, thereby reducing the amount detectable in the sol phase of the sample. Further studies will be necessary to clarify these possibilities. Examination of the other subclass data for these two patients revealed that the first patient had detectable levels of all other subclasses although the sputum to serum ratio for $\operatorname{IgG}_{1}$ compared with albumin was less than $0.6 \quad(0.17)$ which indicates a value below that expected by diffusion alone. Ratios for $\mathrm{IgG}_{2}$ and $\mathrm{IgG}_{3}$ corrected for albumin did, however, indicate some local production ( 0.63 and 1.52 , respectively). The second patient had $\operatorname{IgG}_{1}, \operatorname{IgG}_{2}$, and $\mathrm{IgG}_{3}$ subclass ratios corrected for albumin of 3.1, 1.8 , and 2.4 , respectively, suggesting that the deficiency was restricted to $\operatorname{IgG}_{4}$ in this patient.

Closer study of individual data from the remaining patients indicated that five $(11 \%)$ and three $(7 \%)$ had $\operatorname{IgG}_{1}$ and $\mathrm{IgG}_{2}$ ratios of 0.6 or less compared with albumin. In the $\mathrm{IgG}_{2}$ group one of the observed low ratios was associated with a marked increase in protein transudation which can overwhelm evidence of local production. ${ }^{15}$ In the other patients the low ratio compared with albumin may again represent local consumption of antibody by binding to bacterial antigens.

The interpretation of these sputum results remains uncertain at present. There can be no normal range available for IgG subclasses in sputum although Merrill et $a l^{3}$ have studied IgG subclasses in normal lavage samples. The authors concluded that there was clear evidence for local production of $\mathrm{IgG}_{3}$ and $\mathrm{IgG}_{4}$ in the lung. Review of the data suggests that the lavage and serum values for albumin and $\mathrm{IgG}_{1}$ and $\mathrm{IgG}_{2}$ were similar (ratio of 1.0) and the authors concluded that their data did not indicate local production of these subclasses. They did not take into account, however, the larger size of IgG compared with albumin and hence their data, like ours, indicate a degree of local production of all subclasses even in health. Nevertheless, the added complication of disease makes it uncertain whether the results presented here represent the expected or a suboptimal response to bronchiectasis. We are therefore unable to determine whether the IgG subclass concentrations found in sputum from patients with bronchiectasis are lower than would be expected in the secretions of patients with the presence of an ongoing inflammatory response without a previous history of chronic or recurrent infection. Further studies are indicated to compare the degree of local production of each subclass and, more appropriately, the specificity and function of each of the subclasses, particularly at the site of infection within the lung where the effectiveness of antibody dependent clearance mechanisms will be critical for the removal of bacteria. The relationship between IgG and IgA concentrations and function in the airways will also be important and would determine whether quantitative or qualitative local immunoglobulin deficiency, rather than systemic deficiency, can be implicated in the disease process.

The authors wish to acknowledge the financial support of the United Birmingham Hospitals Endowment Fund, the British
Lung Foundation and the General Hospital Bicentenary Appeal Lung Foundation and the General Hospital Bicentenary Appeal
Fund. Grateful thanks also to Mrs Esther Ford for help in the Fund. Grateful thanks also to
preparation of the manuscript.

1 Popa V, Kim MD, Heiner DC. IgG deficiency in adults with recurrent respiratory infections. Ann Allergy 1993;70:418-

2 Stanley, PJ, Corbo G, Cole PJ. Serum IgG subclasses in chronic and recurrent respiratory infections. Clin Exp Immunol 1984;58:703-8.

3 O'Keefe S, Gzel A, Drury R, et al. Immunoglobulin G subclasses and spirometry in patients with chronic obstructive pulmonary disease. Eur Respir F 1991;4:932-6.

4 Beck CS, Heiner DC. Selective $\mathrm{IgG}_{4}$ deficiency and recurrent infections of the respiratory tract. Am Rev Respir Dis 1981;124:94-6.

5 Oxelius V-A. Chronic infections in a family with hereditary deficiency of $\operatorname{IgG}_{2}$ and $\mathrm{IgG}_{4}$. Clin Exp Immunol 1974;17:1927.

6 Oxelius V-A. IgG subclass levels in infancy and childhood. Acta Paediatr Scand 1979;68:23-7.

7 French MAH, Harrison G. Serum IgG subclasses in French MAH, Harrison G. Serum IgG subclasses in
patients with an increased susceptibility to respiratory tract nfections. Aust NZ F Med 1987;17:402-6.

8 Jeffries R, Kumararatne DS. Selective IgG subclass deficiency: quantification and clinical relevance. Clin Exp Immunol 1990;81:357-67.

9 French MAH, Harrison G. Serum IgG subclass concentrations in healthy adults: a study using monoclonal antisera. Clin Exp Immunol 1984;56:473-7.

10 Stockley RA. Bronchiectasis: new therapeutic approaches based on pathogenesis. Clin Chest Med 1987;8:481-94.

11 Hilton AM, Doyle L. Immunological abnormalities in bronchiectasis with chronic bronchial suppuration. $\mathrm{Br} f \mathrm{Di}$ Chest 1978;72:207-16.

12 Murphy MB, Reen DJ, Fitzgerald MX. Atopy, immunological changes, and respiratory function in bronchiectasis. Thorax 1984;39:179-84.

13 de Gracia J, Rodrigo MJ, Morell F, et al. IgG subclass deficiencies associated with bronchiectasis. Am $\mathcal{F}$ Respir Crit Care Med 1996;153:650-5.

14 Hill SL, Morrison HM, Burnett D, et al. Short term response of patients with bronchiectasis to treatment with amoxycillin given in standard or high doses orally or by inhalation. Thorax 1986;41:559-65.

15 Stockley RA. Measurement of soluble proteins in the lung secretions. Thorax 1984;39:241-7.

16 Plebani A, Ugazio AG, Avanzini MA, et al. Serum IgG subclass concentrations in healthy subjects at different ages. Eur 7 Paediatr 1989;149:164-7.

17 Sontar CA. Distribution of plasma cells and other cells containing immunoglobulin in the respiratory tract in chronic bronchitis. Thorax 1977;32:387-96.

18 Nijhuis-Heddes JMA, Lindeman J, Otto AJ, et al. Distribution of immunoglobulin-containing cells in the bronchial mucosa of patients with chronic respiratory disease. Eur $\mathcal{F}$ Respir Dis 1982;63:249-56.

19 Stockley RA, Hill SL, Morrison HM, et al. Elastolytic activity of sputum and its relation to purulence and lung function in patients with bronchiectasis. Thorax 1984:39:40813

20 Burnett D, Hill SL, Bradwell AR, et al. IgA subclasses in sputum from patients with bronchiectasis. Respir Med 1990; 84:123-7.

21 Bonoma L, D'Addabbo A. $\mathrm{I}^{131}$-albumin turnover and loss of protein into the sputum in chronic bronchitis. Clin Chim Acta 1964;10:214-22.

22 Stockley RA, Mistry M, Bradwell AR, et al. A study of plasma proteins in the sol-phase of sputum from patients with chronic bronchitis. Thorax 1979;34:777-82.

23 Merrill WW, Naegel GP, Olchowski JJ, et al. Immunoglobulin $\mathrm{G}$ subclass proteins in serum and lavage of normal subjects. Am Rev Respir Dis 1985;131:584-7. 